\title{
Nutrient losses from cattle co-digestate slurry during storage
}

\author{
Francesca Perazzolo, Gabriele Mattachini, Fulvia Tambone, Aldo Calcante, Giorgio Provolo \\ Department of Agricultural and Environmental Sciences, University of Milano, Italy
}

\begin{abstract}
Among environmental issues related to intensive livestock activity, emissions to air from manure management are of increasing concern. Thus the knowledge of the effect of treatment application on subsequent emissions from manure is required to assess the environment impact of management solutions. This work addresses the effect of anaerobic digestion and phase separation on emissions during storage by studying nitrogen losses from lab-scale stores and field pilot-scale stores of a co-digestate cattle slurry and its respective separated fractions. Lab-scale experiment was carried in temperature-controlled room where each fraction (untreated, separated liquid and separated solid) was stored in duplicate for a period of 32 days in $30 \mathrm{~L}$ vessel. Pilot-scale experiment was carried out both during the cold season and during warm season for 90 days of storage. In both experimentations samples of the manure were analysed periodically for total Kjeldahl nitrogen (TKN), total ammonia nitrogen, dry matter and volatile solids and $\mathrm{pH}$. These analyses allow estimating nitrogen losses in different
\end{abstract}

Correspondence: Francesca Perazzolo, Department of Agricultural and Environmental Sciences, University of Milano, via G. Celoria 2, 20133 Milano, Italy.

Tel.: +39.02.5031.6858 - Fax: +39.02.5031.6845.

E-mail: francesca.perazzolo@unimi.it

Key words: Digestate; mechanical separation; nutrient loss; greenhouse gas; manure management.

Acknowledgements: the authors would like to thank the staff of Azienda Mezozzi, Landriano (PV) and Azienda Rinaldi, Lodi Vecchio (LO) for their kind support.

Funding: this study was carried out under the project Definition of best practices at low emissions for the management and agronomic utilisation of manure (NERO) granted by the Lombardy Regional Government and the project Multi-regional solution to improve the environmental and economic sustainability of PIG manure management in the Regional of the Po and Veneto basin, supported by Progetto AGER, grant no. 2010-2220.

Contributions: the authors contributed equally.

Received for publication: 16 July 2015.

Accepted for publication: 9 October 2015.

(C) Copyright F. Perazzolo et al., 2016

Licensee PAGEPress, Italy

Journal of Agricultural Engineering 2016; XLVII:500

doi:10.4081/jae.2016.500

This article is distributed under the terms of the Creative Commons Attribution Noncommercial License (by-nc 4.0) which permits any noncommercial use, distribution, and reproduction in any medium, provided the original author(s) and source are credited. storage conditions. Effects of mechanical separation and season were assessed by ANOVA (Wilcoxon test, $\mathrm{P}<0.05$ ). In temperature controlled conditions nitrogen losses measured account for $13 \%$ and $26 \%$ of TKN for unseparated and separated slurries respectively. In field conditions during cold season nutrient losses were limited. On average unseparated and separated slurries lost respectively $6.8 \%$ and $12.6 \%$ of their initial TKN content. Much higher were the TKN losses from the slurries examined in warm season where losses raised up to $40 \%$ of the initial TKN content. Generally mechanical separation increases nutrient losses, but the differences were not significant in field conditions. The results highlighted that nutrient losses, in particular the nitrogen ones, can be considerable especially during summer storage. The latter, in case of separated slurries, are mainly related to the liquid fraction, which is responsible for up $92 \%$ of the losses. When phase separation after anaerobic digestion is used, mitigation options, as covers or slurry acidification, are advisable in order to limit the negative environmental impact.

\section{Introduction}

Manure slurry storage is an important source of greenhouse gas and ammonia $\left(\mathrm{NH}_{3}\right)$ emissions, especially in regions where a storage cover is not compulsory and livestock production is very intensive (e.g., northern Italy). The European Union Nitrates Directive (European Commission, 1991) requires member states to establish a minimum duration of manure storage in order to reduce emissions of nutrients and pollutants to the environment, and balance the nutrient needs of plants with applications of those nutrients. In Italy, a minimum of 180 days is imposed for the storage of liquid effluents and 90 days for the solid fraction.

Mechanical separation and anaerobic digestion (AD) of manure are widely practiced treatments on farm facilities across Europe. For example, $90 \%$ of pig slurry in Greece, $10 \%$ of all animal slurry in Spain and $15 \%$ of cattle slurry and $40 \%$ of pig slurry in Italy are subjected to mechanical separation (Burton and Turner, 2003). The widespread adoption of this technology is mainly related to the ease with which the resulting liquid fraction can be handled. Likewise, anaerobic digestion for biogas production is expanding in several countries thanks to incentive policies that promote green energy and waste management, but the proportion of livestock slurry that is treated using $\mathrm{AD}$ varies greatly. Germany and Italy, with 8700 and $1274 \mathrm{AD}$ plants, respectively, at the end of 2012 (European Biogas Association, 2013) are the EU member states where this technology has the largest success.

Some previous studies (Dinuccio et al., 2008; Fangueiro et al., 2008) have addressed mechanical separation of animal manure but few have studied the application of this technology on digestate from anaerobic digesters. Further, there are few studies that have monitored nutrient losses from manure in completely open field conditions for both winter and summer seasons.

This paper reports research that determined nitrogen losses from the storage of a digested livestock slurry (digestate) and its separated 
liquid and solid fractions, under field and laboratory conditions underlining the differences of the two experimental setup The study results are particularly relevant to improving the precision of emission inventories, which usually are based on a standard methodology that uses default emission factors and is not country-specific. Furthermore the standard methodology considers only the slurry origin and not the effects of any treatment that might have been applied.

\section{Materials and methods}

The study was conducted at the experimental farm A. Menozzi [Landriano (PV), Italy; $45^{\circ} 19^{\prime} 16.5^{\prime}$ N, $9^{\circ} 15$ '56.4" E] of the University of Milan. Lab-scale experiments took place in a temperature-controlled room while experiments in field conditions took place over two time periods. Period 1 (autumn-winter) extended from 1 November 2013 to 30 January 2014. Period 2 (spring-summer) extended from 8 May 2014 to 31 July 2014.

\section{Design of lab-scale and pilot-scale storage facility}

In order to compare emissions from the untreated and separated digested slurries two experimentations were conducted; the first one in temperature controlled conditions while the second in field conditions. In the first case the temperature was set according to the annual average of maximum temperatures $\left(17^{\circ} \mathrm{C}\right)$ in Pianura Padana, an area with intensive livestock activity. The three fractions, unseparated slurry (UN), liquid fraction (LF) and solid fraction (SF) were stored in duplicate (total of 6 vessels) inside $35 \mathrm{~L}$ plastic open vessels (Figure 1) (operative volume: $25 \mathrm{~L}$, open surface $0.096 \mathrm{~m}^{2}$ ) for a period of 32 days.

In field conditions a pilot-scale storage facility was designed to provide accurate and reproducible data on nutrient losses from anaerobically digested slurry and from its mechanically separated liquid and solid fractions. The storage facility was situated in an open field $30 \mathrm{~m}$ from the nearest livestock building. The apparatus was comprised of 4 stainless steel cylindrical storage units (OscarInox1000, ToscanaInox, Firenze, Italy) for the digested slurry and its liquid fraction, and 2 heavy-duty PVC and polyester square containers with triple-layer side walls enclosed in a metal frame (Bestway s.r.l., Milano, Italy) for the solid fraction of the digestate (Figure 1). An office module located next to the storage units housed equipment for regulating and monitoring gaseous emissions from the storage units.

\section{Slurry and storage management (treatments)}

The digested slurry (digestate) was collected from a biogas plant $(250 \mathrm{~kW})$ at a nearby commercial dairy farm [Lodi Vecchio (LO), Italy]. The anaerobically co-digested slurry (UN) (90\% cattle slurry, $10 \%$ corn silage) was mechanically separated using a roller press that generated LF and SF. Mechanical separation took place on the commercial farm 24 $\mathrm{h}$ before the beginning of each storage period. Co-digested slurry and the liquid and solid fractions therefrom were transferred to experimental facilities. For the pilot-scale storage facility a conventional spreading equipment (slurry tanker) was used for the transport. The 4 cylindrical storage units were filled with liquid slurries (UN and LF) to 0.95 $\mathrm{m}$ height, corresponding to $0.8 \mathrm{~m}^{3}$ each, while the four square containers were filled with SF to obtain a pyramidal pile (height of $1 \mathrm{~m}$ ) corresponding to $250 \mathrm{~kg}$ each.

\section{Temperature measurement and climate data}

In the lab-scale experiment the temperatures of the different fractions were recorded continuously using temperature sensors connected to a data-logger at 30-min intervals (HOBO U12, Onset Computer
Corp., Bourne, MA, USA). One sensor was used for each vessel, positioned at $15 \mathrm{~cm}$ depth.

In field conditions temperature in each container was recorded every 30 min throughout each storage period using a temperature sensor (TMC6-HD, Onset Computer Corp.) located $0.3 \mathrm{~m}$ beneath the surface of samples and connected to a data logger (HOBO U12-006, Onset Computer Corp.), which was connected to a computer. Climate data (air temperature, air humidity, precipitation, wind speed and direction, and barometric pressure) were obtained using two portable climate stations (Vantage Pro2 Station, Davis Instruments Corp., Hayward, CA, USA), which were installed in the midst of the storage containers at 1.8 $m$ height above the base of the complex. Climate data were recorded every 5 min throughout each storage period.

\section{Manure analyses and nutrient losses}

In both experiments samples were analysed for total solid (TS, \% fresh manure), volatile solids (VS, \% fresh manure), total Kjeldhal nitrogen (TKN, $\mathrm{g} \mathrm{kg}^{-1}$ ), total ammonia nitrogen (TAN, $\mathrm{g} \mathrm{kg}^{-1}$ ), phosphorous ( $\left.\mathrm{P}, \mathrm{g} \mathrm{kg}^{-1}\right)$, potassium $\left(\mathrm{K}, \mathrm{g} \mathrm{kg}^{-1}\right)$ and $\mathrm{pH}$ according to standard methods (APHA et al., 2005). The levels of uncertainty for these analyses, expressed as relative standard deviations, were $0.3 \%, 1.4 \%, 1.1 \%$ and $1.2 \%$ for TS, VS, TKN and TAN, respectively. All chemical data were adjusted to account for the volume reduction (caused by evaporation) and the volume increase (due to rainfall) during the storage periods.

In lab scale experiments samples were taken after 1 min of mixing once a week and at the end of the investigation period, while in field conditions samples were taken once every 14 days. Before sampling, tanks were thoroughly stirred with a mixer for about 6 min once each week during each storage period, while SF samples were mixed manually. During each sampling day the following measurements were taken: i) pH (at $2 \mathrm{~cm}$ depth and at $30 \mathrm{~cm}$ depth); slurry level in UN and LF treatments (for evaporation rate estimation); visual observations and photographs of the different treatments (for describing the status of the superficial layer, specifically the presence or absence of a crust on UN and LF treatments).

\section{Effect of separation and season}

The effects on nitrogen losses of mechanical separation were evaluated by analysing mass balances for nitrogen (N) based on TAN, TKN and analyses at the start and end of each storage period. Mass losses of $\mathrm{N}$ were expressed both as total losses and as fractions of the initial TKN and TAN content. Losses from the two separated fractions (LF and SF samples from respective disturbed and undisturbed treatments) were mathematically combined, considering the mass separation efficiency

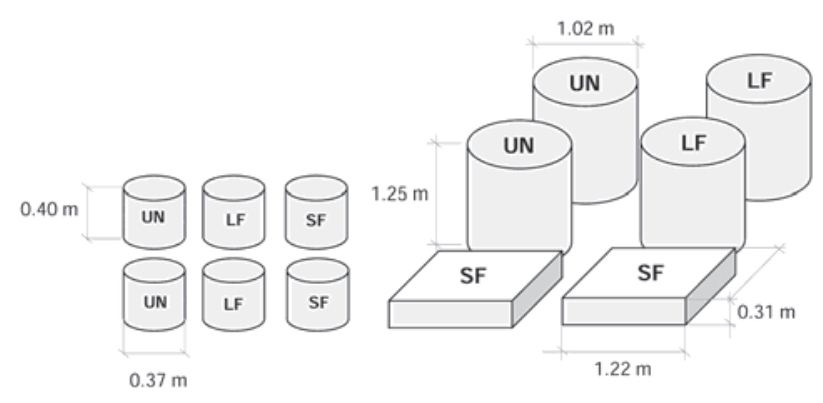

Figure 1. Lab-scale stores which comprised six thirty litre vessels (left) and pilot-scale storage complex (right), with four cylindrical storage units for digested slurry and its liquid fraction, and two square storage units for the solid fraction. UN, unseparated digestate; LF, liquid fraction; SF, separated digestate. 
$(10.9 \pm 2.1 \%)$ of the mechanical separator. The combined losses (TR) of mechanically separated digestates (LF and SF samples) were thus comparable with the unseparated digestates (UN samples). The variations in TKN were considered losses to air because in the storage environment the nitrification process is practically absent (Patni and Jui, 1991). Reductions in TAN also can be considered losses, but TAN concentration is also affected by the net mineralisation of organic nitrogen occurring during storage, and therefore can underestimate emissions to the air (Patni and Jui, 1991).

To compare losses from the unseparated (UN) and the separated digestate (LF and SF), the combined losses of the separated fractions $\left(\mathrm{L}_{\mathrm{TR}}\right)$ were calculated using Equation 1:

$$
\mathrm{L}_{\mathrm{TR}}=\mathrm{X}_{1} * \mathrm{~L}_{\mathrm{LF}}+\mathrm{X}_{2}{ }^{*} \mathrm{~L}_{\mathrm{SF}}
$$

where $\mathrm{L}_{\mathrm{TR}}$ is the sum of losses from separated slurries; $\mathrm{L}_{\mathrm{LF}}$ and $\mathrm{L}_{\mathrm{SF}}$ are the losses for the liquid and solid fractions, respectively; $X_{1}$ and $X_{2}$ are the liquid and solid mass separation efficiencies, respectively, of the mechanical separator.

\section{Data analyses}

Statistical analysis was performed using SAS Software for Windows (SAS version 9.4, SAS Institute Inc., Cary, NC, USA). Chemical analyses (TAN, TKN) were compared between treatments. The data were not normally distributed within equal variance (Kolmogorov-Smirnov and Shapiro-Wilk tests, $\alpha=0.05$ ). Accordingly, a Wilcoxon signed ranks non-parametric analysis was carried out to determine significant differences for the effect of mechanical separation (UN $v s$ TR) and season. $P$ values less than 0.05 were considered to be statistically significant in all tests $\left({ }^{* *} \mathrm{P}<0.05 ;{ }^{* *} \mathrm{P}<0.01\right)$.

\section{Results and discussion}

\section{Ambient and sample temperature}

In the temperature controlled room the average temperature of the different fractions during storage was $16.13 \pm 0.98^{\circ} \mathrm{C}$. Temperature inside the solid fractions remained stable, showing that no composting process took place inside the vessels. The temperature profiles throughout the experiment in field condition differed across the two storage periods. For period 1 (autumn-winter), temperature decreased during the first 50 days, after which it remained relatively stable between 3 and $7^{\circ} \mathrm{C}$ until the end of the storage period at $90 \mathrm{~d}$. In contrast, temperatures during storage period 2 were comparatively stable throughout. On average the temperatures of all samples were higher than ambient air. The temperature of solid-fraction samples was highest during the first month of storage, peaking at $39^{\circ} \mathrm{C}$ during the first week of storage period 1; the start of composting activity may explain this phenomenon. Because conditions inside the solid-fraction heaps were not suitable to complete the composting process, temperature declined after its peak. Temperatures of solid-fraction samples were also the most variable, especially in the second storage period (springsummer). The position of the temperature probe (in the centre of the heap) may explain this observation because in late spring-summer conditions temperature stratification is more accentuated, and the superficial layer was drier and the temperature was closer to ambient air temperature (average: $21.4 \pm 0.4^{\circ} \mathrm{C}$ ). As in the first storage period, conditions in period 2 did not foster composting processes. Temperatures of disturbed slurries (UN and LF) and their undisturbed counterparts were not significantly different (data not shown), meaning that crust formation had an insignificant effect on bulk temperature. Both storage periods were characterised by abundant precipitation. A total of 350 and $285 \mathrm{~mm}$ of rain were recorded during storage periods 1 and 2 , respectively, when for the same periods, averages of 224 and $230 \mathrm{~mm}$, respectively, are usually observed (ARPA, 2015). In particular, the summer season experienced an average daily temperature that was lower than is typical of the area where experiments took place.

\section{Manure characteristics and changes during storage}

The digestate (and its separated fractions) used in both experimentations was drawn from a commercial farm and characteristics in terms of total solids, total nitrogen and ammonia nitrogen content are presented in Table 1. Although all samples came from the same farm, the characteristics were slightly different in the different periods; this would be a typical observation on actual farms as animal diets, feed intake, water management, etc. may change slightly with time.

Mechanical separation leads to SF rich P and organic matter (VS), and to a liquid fraction that is rich in soluble nitrogen. The total solids were in the narrow ranges $6.5-6.3 \%, 5.2-4.2 \%$, and $14.9-16.7 \%$ for UN, LF, SF, respectively (Table 1). Also for the other parameters a low variability was observed. On average UN, LF, SF contained $2.04 \pm 0.11$, $2.03 \pm 0.07$, and $1.18 \pm 0.63 \mathrm{~g} \mathrm{~kg}^{-1}$ of TAN, respectively, and $3.63 \pm 0.16$, $3.36 \pm 0.18,4.07 \pm 0.52 \mathrm{~g} \mathrm{~kg}^{-1}$ of TKN, respectively. The TAN contents of the solid fractions in field conditions were very different between the two storage periods due to technical problems. Storage period 1 effectively started one week after the arrival of digestate and its separated fractions on the experimental farm, during which time SF lost a considerable amount of ammonia nitrogen. The concentration of the latter at the moment of the arrival amounted to approximately $0.7-0.75 \mathrm{~g} \mathrm{~kg}^{-1}$, which however, was still lower than the initial TAN content of solid fractions used in the other experiments.

Among the materials investigated (UN, LF and SF), the liquid fractions were always characterised by the highest initial TAN/TKN ratio $(0.60 \pm 0.04$ for $\mathrm{LF} ; 0.53 \pm 0.016$ for $\mathrm{UN}$; and $0.27 \pm 0.13$ for SF).

Table 1. Untreated slurries, liquid fractions and solid fractions compositions at the beginning of the storage period. Mean and standard deviations (in brackets) of replicates are given.

\begin{tabular}{|c|c|c|c|c|c|c|c|c|c|}
\hline & Sample & $\mathrm{pH}$ & TS $(\%$ tq) & VS $(\%$ tq) & TAN (g/kg) & TKN (g/kg) & TAN/TKN & P (g/kg) & K (g/L) \\
\hline Lab-scale exp. & $\begin{array}{l}\text { UN } \\
\text { LF } \\
\text { SF }\end{array}$ & $\begin{array}{l}8.24(0.02) \\
8.14(0.02) \\
8.91(0.01)\end{array}$ & $\begin{array}{l}6.26(0.15) \\
4.18(0.06) \\
14.9(0.08)\end{array}$ & $\begin{array}{l}4.59(0.15) \\
2.73(0.04) \\
12.73(0.1)\end{array}$ & $\begin{array}{l}1.66(0.06) \\
1.84(0.01) \\
1.84(0.00)\end{array}$ & $\begin{array}{l}3.49(0.11) \\
3.09(0.08) \\
4.56(0.15)\end{array}$ & $\begin{array}{l}0.48 \\
0.59 \\
0.40\end{array}$ & $\begin{array}{l}0.22(0.02) \\
0.21(0.01) \\
0.38(0.02)\end{array}$ & $\begin{array}{l}2.58(0.16) \\
1.95(0.02) \\
1.70(0.05)\end{array}$ \\
\hline Field exp. Period 1 & $\begin{array}{l}\text { UN } \\
\text { LF } \\
\text { SF }\end{array}$ & $\begin{array}{l}8.01(0.01) \\
8.29(0.02) \\
8.88(0.05)\end{array}$ & $\begin{array}{l}6.58(0.22) \\
5.16(0.04) \\
16.7(0.13)\end{array}$ & $\begin{array}{l}4.88(0.19) \\
3.64(0.04) \\
14.54(0.1)\end{array}$ & $\begin{array}{l}1.96(0.16) \\
2.17(0.27) \\
0.38(0.07)\end{array}$ & $\begin{array}{l}3.55(0.07) \\
3.35(0.07) \\
3.40(0.14)\end{array}$ & $\begin{array}{l}0.55(0.06) \\
0.65(0.07) \\
0.11(0.02)\end{array}$ & $\begin{array}{l}\text { nd } \\
\text { nd } \\
\text { nd }\end{array}$ & $\begin{array}{l}\text { nd } \\
\text { nd } \\
\text { nd }\end{array}$ \\
\hline Field exp. Period 2 & $\begin{array}{l}\text { UN } \\
\text { LF } \\
\text { SF }\end{array}$ & $\begin{array}{l}8.47(0.04) \\
8.51(0.04) \\
9.10(0.01)\end{array}$ & $\begin{array}{l}6.29(0.04) \\
5.01(0.13) \\
16.2(0.04)\end{array}$ & $\begin{array}{l}4.54(0.02) \\
3.32(0.06) \\
13.8(0.12)\end{array}$ & $\begin{array}{l}2.14(0.03) \\
2.08(0.03) \\
1.33(0.06)\end{array}$ & $\begin{array}{l}3.85(0.06) \\
3.68(0.05) \\
4.25(0.01)\end{array}$ & $\begin{array}{l}0.55(0.00) \\
0.56(0.02) \\
0.31(0.01)\end{array}$ & $\begin{array}{l}0.67(0.01) \\
0.66(0.02) \\
0.91(0.07)\end{array}$ & $\begin{array}{l}2.77(0.13) \\
2.61(0.27) \\
2.85(0.17)\end{array}$ \\
\hline
\end{tabular}

TS, total solid; VS, volatile solids; TAN, total ammonia nitrogen; TKN, total Kjeldahl nitrogen; P, phosphorous; K, potassium; exp., experiment; UN, untreated slurries; LF, liquid fractions; SF, solid fractions; nd, not determined. 


\section{Lab-scale experiment in controlled temperature conditions}

TAN and TKN of the liquid effluents (UN and LF) showed a slow and constant reduction with time (Figure 2). Contrarily, for the solid fractions the reduction was more marked. SF after the second week showed a marked reduction of TAN concentration, which decreased from 1.26 to $0.42 \mathrm{~g} \mathrm{~kg}^{-1}$. Similar results were also obtained by Hansen et al. (2006), who reported significant reductions in TAN content of the solid fraction during storage. The volatilisation of $\mathrm{NH}_{3}$, stimulated by the aerobic environment of the storage conditions due to the porosity of SF, may explain this observation. Part of this reduction might be also explained by $\mathrm{N}$ immobilisation, because of the high $\mathrm{C} / \mathrm{N}$ ratio of the solid fraction (Fangueiro et al., 2008).

An initial decrease was observed in slurry $\mathrm{pH}$ for all samples (Figure 3). Considering all the data, $\mathrm{pH}$ variations were relatively limited with values between 7.9 and 8.2. During the last two weeks of storage the materials showed a pH decreasing. An initial $\mathrm{pH}$ reduction was also reported by Moset et al. (2012) and Patni and Jui (1991); at the beginning when the storage vessels are filled, the degradation of the organic matter causes volatile fatty acids (VFA) production and thus a $\mathrm{pH}$ reduction. The process of $\mathrm{NH}_{3}$ emission can also have the same effect. The subsequent $\mathrm{pH}$ increment, as reported by Blanes-Vidal et al. (2009), may be connected to two different processes: a reduction in VFA and the emission of carbon dioxide $\left(\mathrm{CO}_{2}\right)$. The latter is more volatile than $\mathrm{NH}_{3}$ and has a lower resistance to transport through the gas phase boundary than $\mathrm{NH}_{3}$. Thus during the storage period observed it seems that the $\mathrm{pH}$ varied, if only over a very limited range, due to the prevalence of one mechanism over the other. This can explain the slight $\mathrm{pH}$ decrease in the first week, when the production of VFA and $\mathrm{NH}_{3}$ emissions might prevail over the effect of $\mathrm{CO}_{2}$ emission. From the second week, the $\mathrm{pH}$ increase is probably because of a reduction in VFA. In any case, sepa-
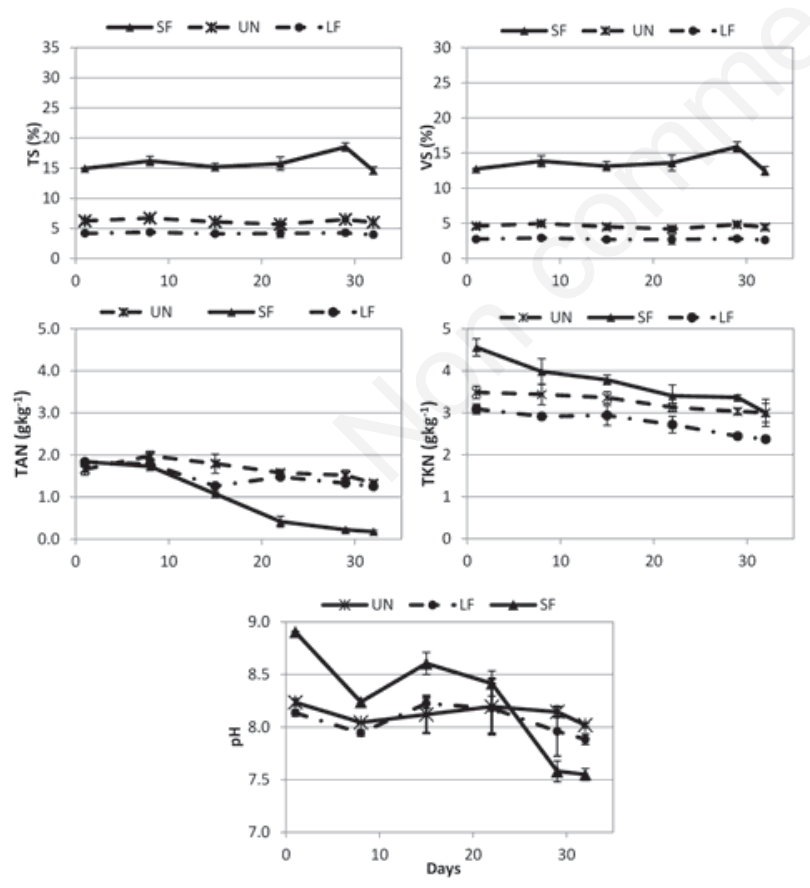

Figure 2. Chemical parameters of materials during lab-scale experiment: total solid (TS), volatile solids (VS), total ammonia nitrogen (TAN), total Kjeldahl nitrogen (TKN) and pH. Data are expressed on a fresh weight basis and are averages of results from duplicate containers for each material type. Material types were: unseparated digestate (UN), liquid fraction (LF) of mechanically separated digestate and solid fraction of separated digestate $(\mathrm{SF})$. ration did not show any effect on $\mathrm{pH}$ trends. An initial $\mathrm{pH}$ reduction was also reported by other authors (Patni and Jui, 1991; Moset et al., 2012) and attributed to the degradation of organic matter just after storage tanks are first filled, which causes VFA production and thus a pH reduction. Thereafter, oxidation of VFA may cause the $\mathrm{pH}$ to increase as some of the acids are removed (Paul and Beauchamp, 1989). When VFAs decrease, the importance of the bicarbonate/carbonate $\left(\mathrm{HCO}_{3}{ }^{-} / \mathrm{CO}_{3}{ }^{-}\right)$) buffer system increases, and thus the emission of $\mathrm{CO}_{2}$ causes a pH increment.
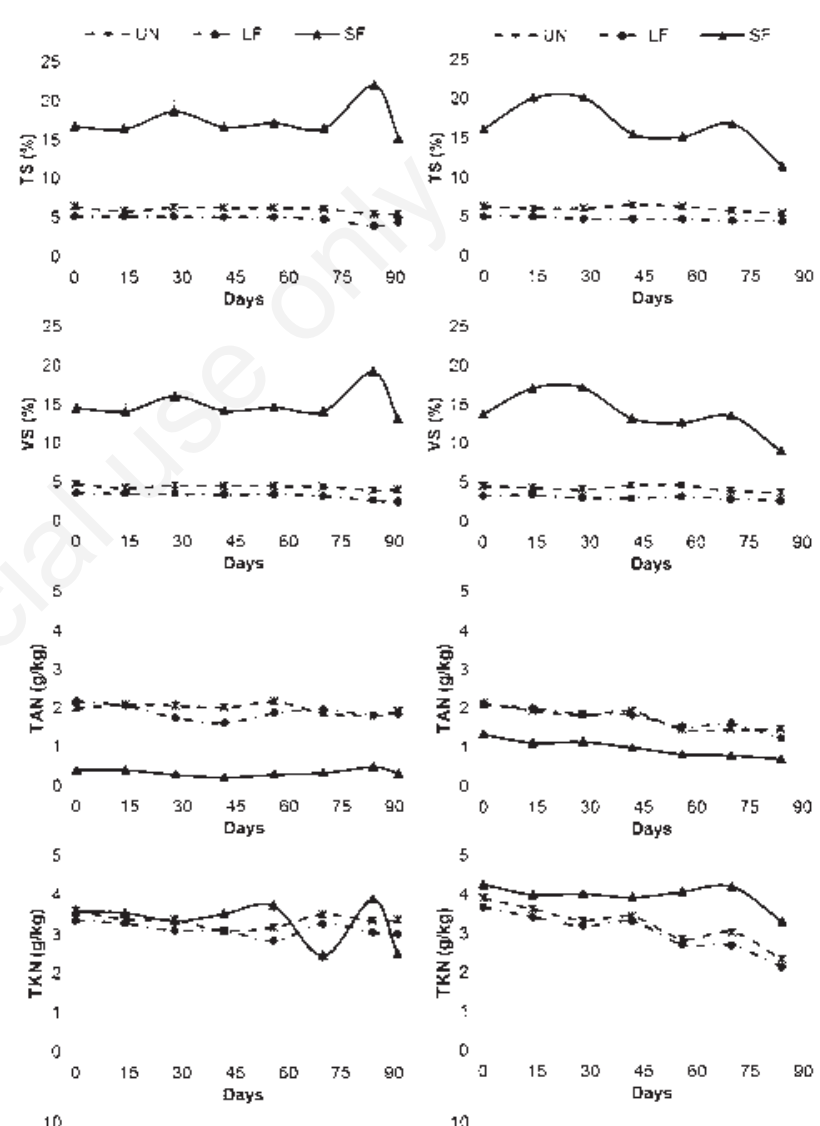

10
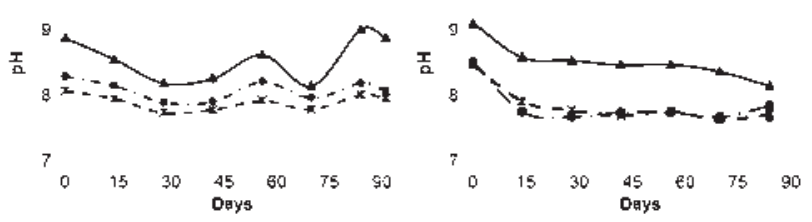

Figure 3. Chemical parameters of materials during storage periods 1 (left) and 2 (right): total solid (TS), volatile solids (VS), total ammonia nitrogen (TAN), total Kjeldahl nitrogen (TKN) and $\mathrm{pH}$. Data are expressed on a fresh weight basis and are averages of results from duplicate containers for each material type. Material types were: unseparated digestate (UN), liquid fraction (LF) of mechanically separated digestate and solid fraction of separated digestate $(\mathrm{SF})$. 
Pilot-scale experiments in field conditions

Figure 3 shows the variation in chemical parameters during each storage period.

During storage period 1 (autumn-winter), TS, VS tended to remain stable indicating that the climatic conditions did not promote organic matter degradation and thus carbon emission. However, TKN and TAN decreased slightly over the course of this period, indicating that small nitrogen losses probably took place. Solid-fraction analyses showed trends less regular than UN and LF: this may be due to the very different conditions of the heaps during sampling. Although we took samples immediately after mixing, different heaps presented very variable characteristics.

The highest $\mathrm{pH}$ values were recorded in all samples during storage period 2. The $\mathrm{pH}$ of digestate (UN) varied between 8 and 8.5 while LF and SF samples exhibited $\mathrm{pH} 8.3-8.5$ and 8.9-9.1, respectively. In both storage periods, $\mathrm{pH}$ decreased during the first month of storage, after which $\mathrm{pH}$ tended to increase (except for SF samples in storage period 2). The mechanisms which influence $\mathrm{pH}$ are the same explained previously. After the first month of each storage period, $\mathrm{pH}$ variations were very limited. The average $\mathrm{pH}$ of $\mathrm{LF}, \mathrm{SF}$, and UN was $7.99,8.55$, and 7.85 , respectively, in storage period 1 , and $7.75,8.36$, and 7.70 , respectively, in storage period 2 . The somewhat lower $\mathrm{pH}$ observed during storage period 2 may be explained by the higher carbon and nitrogen losses that occurred compared to period 1 , both of which affected $\mathrm{pH}$. In particular the effect of $\mathrm{NH}_{3}$ loss is to reduce $\mathrm{pH}$, which adds to the VFA production effect. In contrast, carbon dioxide emission together with VFA oxidation reduces $\mathrm{pH}$ (Blanes-Vidal et al., 2009).

Chemical changes in storage period 2 (spring-summer) showed clearer trends, especially for TKN and TAN, than those in period 1. The warm temperature promoted $\mathrm{N}$ losses from all materials. Solid-fraction samples retained part of their TAN contents. The volume of solids stored and self-compaction of the heaps inhibited the complete volatilization of ammonia.

\section{Effects of treatments on nitrogen losses}

Table 2 shows the effect of mechanical separation on nitrogen losses during the storage period, as estimated from the initial and final chemical analyses. As expected, losses of TKN were higher than TAN losses confirming that during the storage period some mineralisation of organic nitrogen occurred. The combined nitrogen losses from the separated fractions were significantly different $(+86 \%)$ than those from the respective unseparated digestates only in temperature controlled conditions, where TR and UN lost $42 \%$ and $20 \%$ of their initial TAN con- tent respectively (Table 2). Considering the separation efficiency, the liquid fractions account for $66 \%$ of total nitrogen loss. As in Fangueiro et al. (2008), these results are mainly due to the losses from the liquid fractions, usually characterized by the highest TAN/TKN ratio and lowest TS contents; Vaddella et al. (2013) found that the $\mathrm{NH}_{3}$ mass transfer coefficient decreases with increasing TS concentration. These results are in accordance with other studies that report higher emission from the separated fractions during storage (Fangueiro et al., 2008; Dinuccio et al., 2008). However in field conditions mechanical separation did not have a significant effect on TKN losses. In storage period 1 a very dilute and wet layer, probably characterised by a very low TAN concentration, formed on the surface of all materials (including the separated solid fractions) further inhibiting gaseous emissions that were already retarded by the low temperatures. In autumn-winter storage period consequently nitrogen losses were limited. The average combined loss of nitrogen, as a percentage of initial TKN were $6.8 \%$ and $12.3 \%$ for UN and TR, respectively. These results are a bit higher than those of Patni and Jui (1991) who observed that in winter, nitrogen losses were between $4.4 \%$ and $8.4 \%$ from two stores filled with dairy slurry left undisturbed for the entire storage period. In the springsummer storage period (period 2), nitrogen losses were significantly higher than in storage period 1 from all materials. Unseparated slurries lost up to $40 \%$ of their initial TKN while the separated ones lost almost $37 \%$ of their initial TKN (Table 2). The results summarised in Table 2 clearly highlight the effect of climatic conditions, with warmer ambient temperatures in particular always causing significantly $(\mathrm{P}<0.05)$ higher nitrogen losses than cooler temperatures. Compared to the losses observed in the present study, VanderZaag et al. (2009) measured TKN losses that were approximately $20 \%$ lower during a 5 -month storage of dairy slurry. Probably these differences can be related to the lower temperatures in Canada than in Italy, and to the longer storage period that was used in the present study.

Compering the TKN losses from unseparated and separated digestates of period 2 of field experiment with those measured at $17^{\circ} \mathrm{C}$, the first ones were 2.8 and 1.4 times higher. Considering that in field conditions the average temperature was higher and the storage period was 3 times longer, in proportion $\mathrm{N}$ losses measured in temperature controlled conditions were higher especially for LF and SF, which lost 23 and $34 \%$ of the TKN content respectively (Table 2). The possible explanations are the following: the lower volumes/surface ratio of the vessels (0.2) than tanks (0.9) and solid fraction containers $(0.35)$, the more frequent mixing operations in lab-scale experiments and the environmental conditions which in field conditions allow the forma-

Table 2. Mean and standard deviations (in brackets) of total Kjeldahl nitrogen and total ammonia nitrogen losses during storage for separated and unseparated slurries.

\begin{tabular}{|c|c|c|c|c|c|c|c|}
\hline & & & UN & LF & SF & TR & $\begin{array}{l}\text { Difference due } \\
\text { to separation } \%\end{array}$ \\
\hline \multirow{4}{*}{\multicolumn{2}{|c|}{ Controlled temperature condition }} & TAN loss $(\mathrm{kg} / \mathrm{t})$ & $0.33(0.11)$ & $0.58(0.00)$ & $1.66(0.02)$ & $0.78(0.01)$ & $137 \%$ \\
\hline & & TAN loss/TANin (\%) & $19.82(5.22)$ & $31.57(0.09)$ & $90.25(1.06)$ & $42.74(0.01)$ & $+116 \% * *$ \\
\hline & & TKN loss (kg/t) & $0.49(0.06)$ & $0.72(0.14)$ & $1.56(0.09)$ & $0.88(0.10)$ & $81 \%$ \\
\hline & & TKN loss/TKNin (\%) & $13.96(2.03)$ & $23.17(3.81)$ & $34.2(3.00)$ & $26.00(2.07)$ & $+86 \% * * *$ \\
\hline \multirow[t]{8}{*}{ Field experiments } & \multirow[t]{4}{*}{ Period 1} & TAN loss $(\mathrm{kg} / \mathrm{t})$ & $0.13(0.05)$ & $0.13(0.03)$ & $0.08(0.00)$ & $0.14(0.03)$ & $+8 \%$ \\
\hline & & TAN loss/TANin (\%) & $6.20(0.02)$ & $6.40(1.53)$ & $19.46(2.48)$ & $6.3(1.15)$ & $+2 \%$ \\
\hline & & TKN loss $(\mathrm{kg} / \mathrm{t})$ & $0.24(0.01)$ & $0.35(0.08)$ & $1.10(0.17)$ & $0.42(0.05)$ & $+75 \%$ \\
\hline & & TKN loss/TKNin (\%) & $6.8 \%(0.0)$ & $10.4 \%(2.1)$ & $30.2 \%(3.5)$ & $12.6 \%(1.5)$ & $+8 \% *$ \\
\hline & \multirow[t]{4}{*}{ Period 2} & TAN loss $(\mathrm{kg} / \mathrm{t})$ & $0.68(0.06)$ & $0.85(0.05)$ & $0.62(0.08)$ & $0.77(0.03)$ & +13 \\
\hline & & TAN loss/TANin (\%) & $31.6(2.3)$ & $40.81(2.82)$ & $46.75(4.41)$ & $41.29(1.07)$ & $+31 \%$ \\
\hline & & TKN loss $(\mathrm{kg} / \mathrm{t})$ & $1.57(0.01)$ & $1.54(0.05)$ & $0.95(0.085)$ & $1.47(0.03)$ & -6 \\
\hline & & TKN loss/TKNin (\%) & $40.1 \%(0.3)$ & $41.9 \%(1.2)$ & $24.2 \%(2.2)$ & $37.6 \%(0.8)$ & $-6 \% *$ \\
\hline
\end{tabular}

UN, untreated slurries; LF, liquid fractions; SF, solid fractions; TR, sum of LF and SF; TAN, total ammonia nitrogen; TKN, total Kjeldahl nitrogen. Mean difference at ${ }^{*} \mathrm{P}<0.10$, ${ }^{* *} \mathrm{P}<0.05 ;{ }^{* * * P}<0.01$. 
tion of superficial layers with more resistance to emissions. Because the liquid effluents are characterized mainly by an anaerobic environment it is possible to state that $\mathrm{N}$ losses occurred mainly as $\mathrm{NH}_{3}$. Therefore TKN losses can be compared with $\mathrm{NH}_{3}$ default emission factor. The nitrogen emission factor reported by ISPRA (2008) for dairy cows from slurry tanks is $23 \%$ of the $\mathrm{N}$ content before storage. In the present study, losses of 6.8 and $40.1 \%$ of the initial TKN were measured in digestate (UN) in winter and summer, respectively. Considering that most of these losses occurred as gaseous emissions of ammonia, the aggregate of the losses over both storage periods yields an emission factor of $46.9 \%$, which is more than 2 times higher than that indicated by ISPRA (2008) for dairy cow slurry. Probably this difference can be related in part to the lower volume/surface ratio of the tanks used than normal stores, but also to the higher TAN concentration and $\mathrm{pH}$ which generally characterise digestates, which suggests a possible underestimation of $\mathrm{NH}_{3}$ emissions from these materials during the summer season.

\section{Conclusions}

The methodology used in this study provided useful information concerning nutrient losses from separated and unseparated digestate in open field storage and in lab-scale conditions.

The two experiments leads to different results, mainly related to the different experimental condition and experimental set up. Lab-scale experiments provide very useful information concerning the comparison of different treatments (e.g., mechanical separation) because they let to isolate only the effects related to the slurry physical and chemical characteristics. From the other side field conditions allow to measure the losses in real conditions and to understand how the other environmental factors can influence the slurry characteristics and thus the emissions. Based on the results obtained from this study it was found that in field conditions mechanical separation did not cause significant difference on $\mathrm{N}$ losses. The different effects observed in lab-scale a in pilot-scale experiments are most likely connected to the state of the superficial layer very different in the two experimental conditions and to the effect of mixing. Surely experiments underline significant losses suggesting that probably the currently recommended ammonia emission factor underestimates the actual emissions from digestates.

These results are particularly relevant for European countries (e.g., Italy) with a high number of biogas plants and mechanical separations installations where the covering of slurry stores and/or acidification of manure is not a common practice. From our study, the major contribution to $\mathrm{N}$ losses were the liquid fractions, which accounted for an average of $66-90 \%$ of the total losses determined. Mitigation of emissions from this source e.g., by covering the storage tanks and/or acidification of the liquid fractions is therefore highly recommended especially on the storage of the liquid fraction of digestates.

\section{References}

APHA, AWWA, WEF. 2005. Standard methods for the examination of water and wastewater, 21st ed. American Public Health Association, Washington, DC, USA.

ARPA (Regional Agency for Environmental Protection of Lombardia), 2015. Daily data of the weather station located in Landriano (temperature and rainfall) for years from 2005-2014. Available from: http://ita.arpalombardia.it/ita/index.asp Accessed: May 2015.

Blanes-Vidal V., Sommer S.G., Nadimi E.S. 2009. Modelling surface pH and emissions of hydrogen sulphide, ammonia, acetic acid and carbon dioxide from a pig waste lagoon. Biosyst. Eng. 104:510-21.

Burton C.H., Turner C. 2003. Manure management - Treatment strategies for sustainable agriculture. Silsoe Research Institute, Bedford, UK.

Dinuccio E., Berg W., Balsari P. 2008. Gaseous emissions from the storage of untreated slurries and fractions obtained after mechanical separation. Atmos. Environ. 42:2448-59.

European Biogas Association. 2013. Biogas production statistics. Available from: http://european-biogas.eu/2013/12/20/eba-presentslatest-biogas-production-statistics-europe-growth-continuous/ Accessed: May 2015.

European Commission. 1991. Council Directive 91/676/EEC of 12 December 1991 concerning the protection of waters against pollution caused by nitrates from agricultural sources. In: Official Journal, L 375, 31/12/1991, pp 1-8.

Fangueiro D., Coutinho J., Chadwick D., Moreira N., 2008. Effect of cattle slurry separation on greenhouse gas and ammonia emissions during storage. J. Environ. Qual. 37:2322-31.

Hansen M.N., Henriksen K., Sommer S.G. 2006. Observations of production and emission of greenhouse gases and ammonia during storage of solids separated from pig slurry: effects of covering. Atmos. Environ. 40:4172-4181.

ISPRA (Institute for Environmental Protection). 2008. Inventario nazionale delle emissioni e disaggregazione provinciale. ISPRA Press, Roma, Italy [In Italian].

Moset V., Cambra-Lopez M., Estelles F., Torres A.G., Cerisuelo A., 2012. Evolution of chemical composition and gas emissions from aged pig slurry during outdoor storage with and without prior solid separation. Biosyst Eng. 3:2-10.

Patni N.K., Jui P.Y. 1991. Nitrogen concentration variability in dairy-cattle slurry stored in farm tanks. Trans. ASAE 34:609-15.

Paul J.V., Beauchamp E.G. 1989. Relationship between volatile fatty acids, total ammonia, and $\mathrm{pH}$ in manure slurries. Bio. Wastes. 29:313-8.

Vaddella V.K., Ndegwa P.M., Ulman J.L., Jiang A., 2013. Mass transfer coefficient of ammonia for liquid dairy manure. Atmos. Environ. 66:107-13.

VanderZaag A.C., Gordon R.J., Jamieson R.C., Burton D.L., Stratton G.W. 2009. Permeable synthetic covers for controlling emissions from liquid dairy manure. Appl. Eng. Agric. 26:287-97. 